\title{
Is cerebral spinal fluid flow associated with body mass index and head circumference in healthy children? A phase contrast magnetic resonance imaging study
}

\author{
Gökhan Demirtaşs ${ }^{1}$, Ahmet Siğirci ${ }^{1}$, Mehmet Öztürk ${ }^{2^{*}}$ (D), Süreyya Burcu Görkem ${ }^{3}$, Betül Kiliç ${ }^{4}$ and Serdal Güngör ${ }^{4}$
}

\begin{abstract}
Background: The aim of this study was to investigate the relationship between age, gender, body mass index (BMI), and head circumference (HC) and cerebral spinal fluid (CSF) flow dynamics in the pediatric population. The prospective study included a total of 137 participants, 75 boys and 62 girls, ranging in age from 2 to 204 months. Quantitative evaluation of CSF flow was made by using phase contrast magnetic resonance imaging (PC-MRI) in the axial plane at the level of the aqueductus cerebri. Flow dynamics were recorded as peak and mean velocity $(\mathrm{cm} / \mathrm{s})$; cranial, caudal, and net volume $(\mathrm{ml})$; and aqueductus cerebri area $\left(\mathrm{mm}^{2}\right)$. Correlation between baseline descriptive parameters, including age, gender, BMI, and HC, and the aforementioned CSF flow dynamics were investigated.
\end{abstract}

Results: The net volume was significantly lower in girls $(p=0.002)$. There was no association between age and aqueduct area, mean velocity, and cranial volume. The peak velocity was remarkably higher in children $(p=0.03)$, whereas cranial and net volume were found to be lower in infants ( $p=0.04$ and $p=0.03$, respectively). Notably, cases with HC below normal values had lower cranial, caudal, and net volume and aqueductus cerebri area ( $p=$ $0.01, p=0.03, p=0.03$, and $p=0.04$, respectively). There was no association between BMl and indicators of CSF flow dynamics in PC-MRI.

Conclusion: BMI and HC may be associated with CSF flow dynamics in children. A smaller HC is accompanied by a lower forward flow volume, reverse flow volume, net volume, and aqueductal diameter. These points should be remembered during the design of further trials on determinants of CSF flow in children.

Keywords: Magnetic resonance angiography, Cerebrospinal fluid, Flow, Dynamics, Head circumference, Body mass index

\section{Background}

Phase contrast magnetic resonance imaging (PC-MRI) has gained popularity for investigating the physiology and pathologies of cerebrospinal fluid (CSF) flow. Attributed to the sensitivity of this method, studies mainly focused on the ventricular system, subarachnoid spaces,

\footnotetext{
* Correspondence: drmehmet2121@gmail.com

2Department of Radiology, Division of Pediatric Radiology, Faculty of Medicine, Selcuk University, Alaeddin Keykubat Yerleşkesi, Akademi Mah, Yeni Istanbul Street No: 369, Konya, Turkey

Full list of author information is available at the end of the article
}

spinal canal, and aqueductus cerebri, the latter of which has a regular CSF flow [1]. Expression of flow in numeric variables has allowed a better understanding of normal flow patterns and alterations in various pathologies, including normal pressure hydrocephalus, Chiari malformation, and arachnoid cysts [2, 3]. Owing to the popularization of neuroendoscopic interventions, PCMRI was used for investigating the patency of third ventriculostomies and assessing CSF flow following endoscopic aqueductoplasty $[4,5]$.

\section{Springer Open}

๑ The Author(s). 2020 Open Access This article is licensed under a Creative Commons Attribution 4.0 International License which permits use, sharing, adaptation, distribution and reproduction in any medium or format, as long as you give appropriate credit to the original author(s) and the source, provide a link to the Creative Commons licence, and indicate if changes were made. The images or other third party material in this article are included in the article's Creative Commons licence, unless indicated otherwise in a credit line to the material. If material is not included in the article's Creative Commons licence and your intended use is not permitted by statutory regulation or exceeds the permitted use, you will need to obtain permission directly from the copyright holder. To view a copy of this licence, visit http://creativecommons.org/licenses/by/4.0/. 


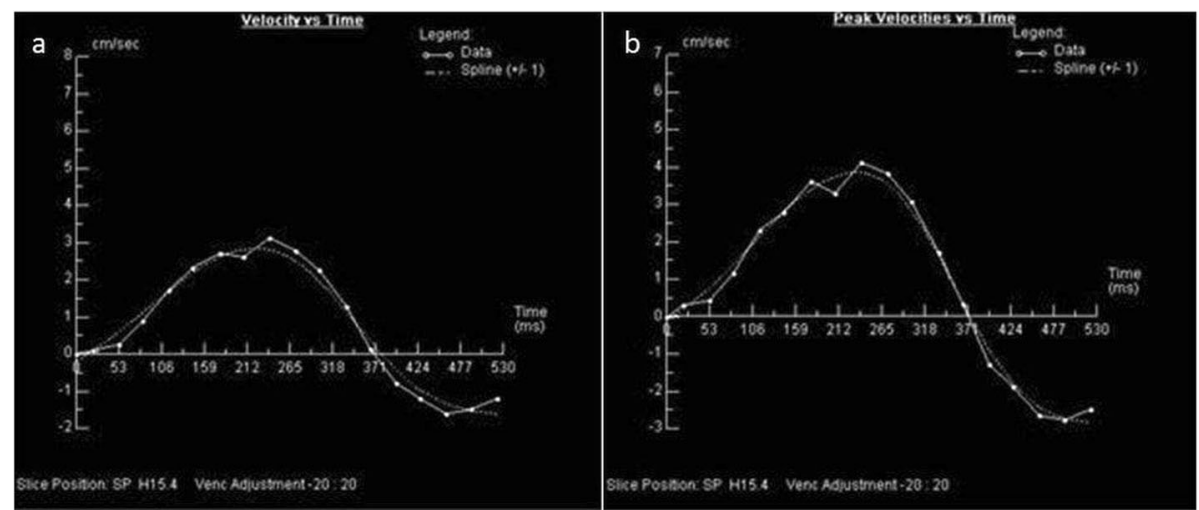

Fig. 1 Graphs for (a) mean velocity versus time and (b) peak velocity versus time

More recent studies are showing the CSF current changes made by PC-MRI in diseases such as idiopathic intracranial hypertension, neuro-Behçet disease, amyotrophic lateral sclerosis, and mucopolysaccharidoses [6-9]. In the relevant literature, the link between CSF pressure and body mass index (BMI) was examined; however, no studies were published on the relationship between CSF flow dynamics, BMI, and head circumference (HC) [10].

The aim of the present study was to evaluate the relationship between CSF flow dynamics, BMI, and HC in a healthy pediatric population.

\section{Methods}

\section{Study design}

This prospective trial was implemented in the pediatric neurology department of our tertiary care center between January 2014 and December 2014. The approval of the local Institutional Review Board (2014/208) was obtained prior to the study. Parents gave written informed consent, and the study strictly adhered to the principles announced in the Helsinki Declaration.
A total of 137 participants were included in the study. To reduce the movement artifact in children, $50 \mathrm{mg} / \mathrm{kg}$ chloral hydrate was administered orally to induce sleep $(n=39)$. A sedative was not used in participants who cooperated $(n=98)$. MRI indications are headache $(n=19)$, epilepsy $(n=15)$, high fever $(n=14)$, dizziness $(n=13)$, gait disturbance $(n=13)$, visual disturbance $(n=12)$, hearing loss $(n=11)$, severe nausea and vomiting $(n=11)$, neuromotor retardation $(n=10)$, loss of strength in extremities $(n=$ $10)$, and convulsion $(n=9)$, respectively. Participants did not have any systemic diseases or cranial pathologies nor were they on any medications. All MRI examinations of the day, the same hour, were made in the morning. PC-MR images were of diagnostic quality in all cases, and no cases were excluded from this study. In the neonatal age group, MRI cases in which brain pathology was detected and continuous drug users were excluded from the study.

$\mathrm{HC}$ was measured by passing the tape just above the participant's eyebrows and round to the occipital pole at the back of the head [11].
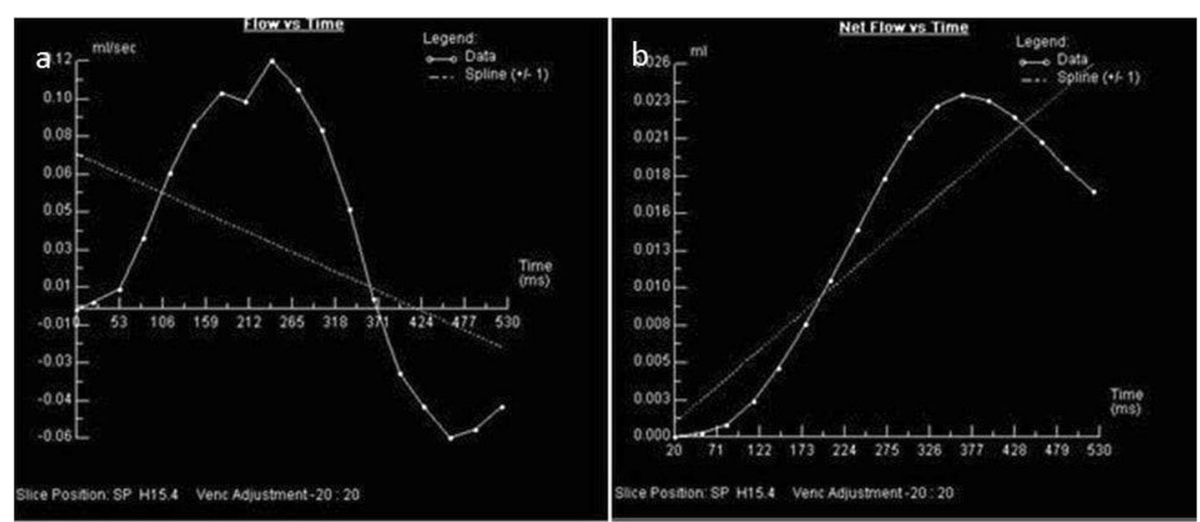

Fig. 2 Graphs for (a) flow versus time and (b) net flow versus time 

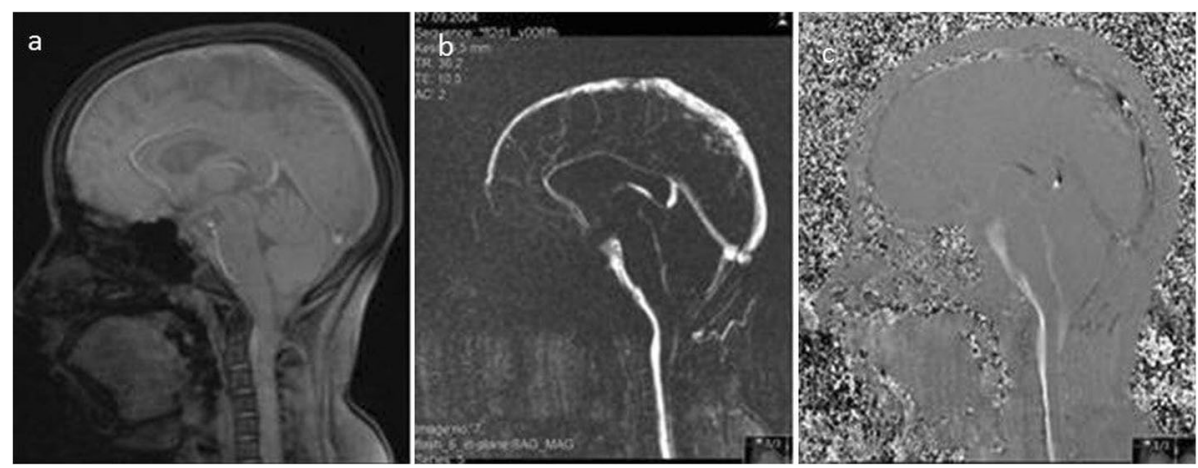

Fig. 3 a Rephase. b Magnitude. c Phase images

\section{Magnetic resonance imaging}

All participants routinely underwent T2-weighted and fluid-attenuated inversion recovery (FLAIR) magnetic resonance imaging (MRI) on the axial plan and PC-MRI. Quantitative evaluation of CSF flow was made with 1.5 Tesla MRI (Magnetom Avanto, Siemens Healthcare, Erlangen, Germany). Images were obtained on the axial plane using standard head coil for 2D Q FLOW phase contrast MR angiography technique.

Duration of PC-MRI was approximately $5 \mathrm{~min}$ for every participant. Former images were obtained on midline in sagittal, coronal, and axial T1 views. Subsequently, average modulus (rephase), the magnitude of the complex difference (magnitude), and directional phase difference (phase) images were obtained on a semi-axial plane perpendicular to the cerebral aqueduct in the sagittal axis. Details of axial MRI images were as follows: TR: $31.25 \mathrm{~ms}$, TE: $8.06 \mathrm{msn}$, slice thickness: 5.5 $\mathrm{mm}$, NSA: 1 , FOV: $16 \times 10 \mathrm{~cm}$, matrix: $128 \times 256$, and deviation angle: 10 degrees. Cardiac phase cuts were taken that varied between 14 and 30 according to the heart rate. Cardiac triggering was made prospectively with finger plethysmography. Velocity encoding (Venc) of PC-MRI was set at $20 \mathrm{~cm} / \mathrm{s}$. The craniocaudal flow was defined as "positive," and the caudocranial direction was defined as "negative."

\section{Analysis of magnetic resonance images}

ARGUS is an image analysis program that evaluates ventricular volume, blood, and CSF flows quantitatively in cine mode. This program measures average forward and reverse flows and average and maximum flow velocities in major and minor vessels and in aqueducts with a regular flow. As seen in Figs. 1 and 2, images obtained via FLASH through in-plane and in-plane sequences were transferred to an ARGUS image analysis program (ARGUS, Siemens Medical Solutions, Erlangen, Germany) on a Leonardo Workstation (Magnetom Avanto, Siemens Medical Solutions, Erlangen, Germany). Phase, rephase, and magnitude images were obtained in semi-axial and sagittal planes (Figs. 3 and 4). Initially, CSF flow was visually evaluated in all participants. For phase and magnitude images, flow with a high signal intensity was observed in a cerebral aqueduct in phase and magnitude views, whereas caudal flow had low signal intensity. Because contrast is more prominent for the CSF flow in aqueduct in phase and magnitude images, regions of interest (ROIs) were placed in a circular shape for each section (Fig. 5). On semi-axial images that occupy the whole aqueduct, velocity $(\mathrm{cm} / \mathrm{s})$ and flow $(\mathrm{ml} / \mathrm{s})$ values and a velocity-flow curve were obtained (Figs. 1 and 2), and average CSF flow was calculated.

Participants that required anesthesia underwent PCMRI under sedo-analgesia, whereas no additional preparations were carried out for participants that did not require anesthesia. Instructions were given to avoid deep inspiration or expiration during imaging.

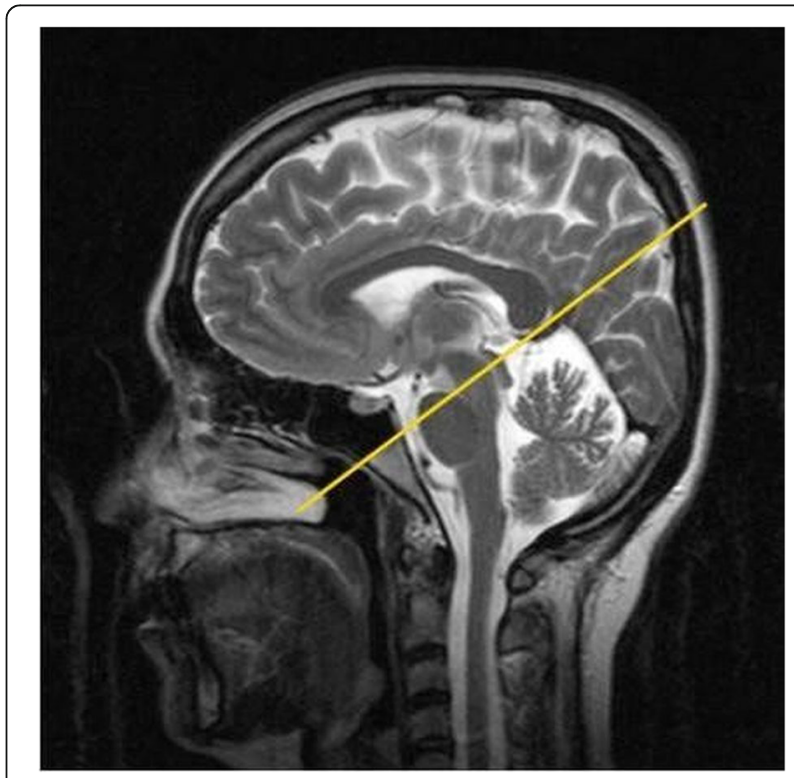

Fig. 4 Semi-axial plane that lies perpendicular to the cerebral aqueduct 


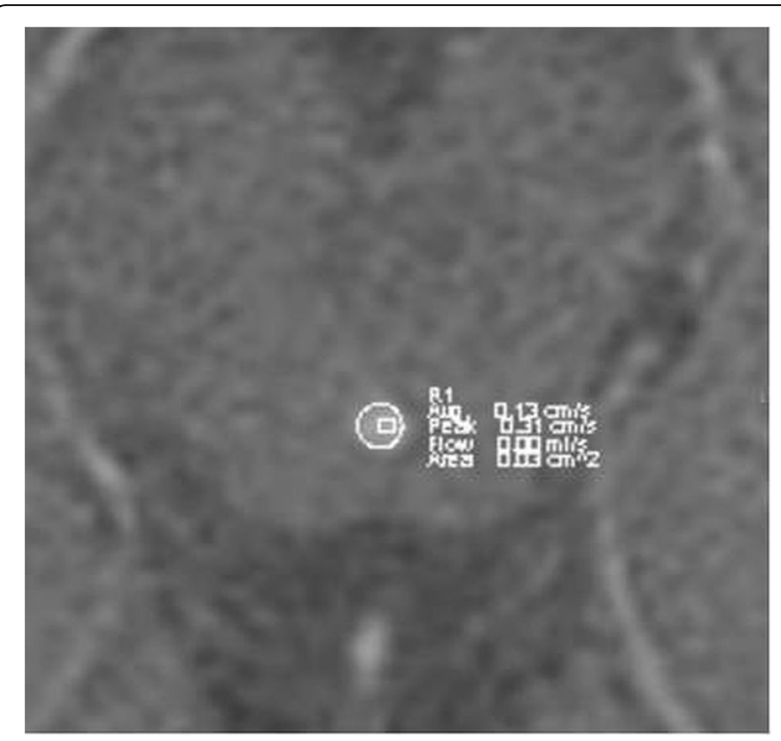

Fig. 5 Establishment of region of interest (ROI) that corresponds to cerebral aqueduct

Eddy flows resulted in distortion of gradient profile and adversely affected the accuracy of encoded images. To minimize the impact of eddy flows, ROIs should be maintained as small as possible [12]. In aqueducts with a small diameter, the likelihood of error increases due to noise and poor contrast.

\section{Statistical analysis}

Analysis of our data was made with Statistical Package for Social Sciences program (SPSS Inc., Chicago, IL, USA), version 17.0. Absolute values were considered for rates. The peak velocity, mean velocity cranial volume, caudal volume, net volume passing through aqueductus cerebri in a cardiac cycle, peak velocity parameters and average aqueductus cerebri area were compared according to age, gender, $\mathrm{HC}$, and BMI groups. Quantitative variables were expressed as mean \pm standard deviation or median-interquartile range. The normal distribution of quantitative variables was evaluated using the Shapiro-Wilk test. Kruskal-Wallis test was used to determine whether there was a significant difference between the mean scores of two dependent groups of one or more dependent variables. The variance analysis was used to test hypotheses about whether the difference between two or more group averages is meaningful. The
Mann-Whitney $U$ test was applied to test whether the values obtained for two independent groups differed significantly from each other. The median values of the groups were compared. Spearman rank correlation test was used to evaluate the strength and direction of the linear relationship between two continuous variables. The level of statistical significance was set at $p<0.05$.

\section{Results}

Our series consisted of 62 girls (45.3\%) and 75 boys (54.7\%) with an average age of 68.8 months (range: 3202). Three groups were constituted with respect to the age of participants: group $1(n=26)$ aged 1 to 12 months, group $2(n=79)$ aged 13 to 120 months, and group $3(n=32)$ aged 121 to 202 months. The average ages in groups 1 to 3 were $9.6 \pm 2.3,52.8 \pm 34.0$, and $156.3 \pm 21$ months, respectively.

Table 1 demonstrates the peak velocity $(5.47 \pm 2.84$ $\mathrm{cm} / \mathrm{sn})$, mean velocity $(0.75 \pm 0.63 \mathrm{~cm} / \mathrm{sn})$, mean forward flow volume $(0.015 \pm 0.013 \mathrm{ml}$ ), mean backward (reverse) flow volume $(0.011 \pm 0.017)$, mean net flow volume $(0.0086 \pm 0.0013 \mathrm{ml})$, and mean aqueductal area $\left(1.96 \pm 0.95 \mathrm{~mm}^{2}\right)$ in PC-MRI.

Comparison of two of these aforementioned variables in males and females yielded that mean net flow volume was less in females $(p=0.002)$. There were no significant differences between the two genders regarding the peak velocity, mean velocity, mean forward flow volume, mean backward (reverse) flow volume, and mean aqueductal area.

As shown in Table 2, comparison of variables in the three age groups showed that group 2 had the highest peak velocity $(p=0.027)$. However, group 1 had lower mean forward flow volume than group $2(p=0.039)$ and group $3(p=0.039)$ and also lower mean net volume than group $2(p=0.029)$ and group $3(p=0.029)$. In contrast, no remarkable difference was detected between group 2 and group 3 with respect to the parameters under investigation.

Two groups were constituted with respect to $\mathrm{HC}$, and with $\mathrm{HC}<3 \%$ were compared with having normal ( $\geq$ $3 \%) \mathrm{HC}$ (Table 3). It turned out that mean forward flow volume $(p=0.008)$, mean reverse flow volume $(p=$ $0.026)$, mean net volume $(p=0.032)$, and aqueductal area $(p=0.038)$ were lower in with $\mathrm{HC}<3 \%$.

Table 1 A comparative overview of phase contrast MRI parameters in females and males

\begin{tabular}{|c|c|c|c|c|c|c|}
\hline Gender & $\begin{array}{l}\text { Peak velocity } \\
(\mathrm{cm} / \mathrm{sn})\end{array}$ & $\begin{array}{l}\text { Mean velocity } \\
(\mathrm{cm} / \mathrm{sn})\end{array}$ & Forward flow volume (ml) & Reverse flow volume (ml) & Net volume (ml) & $\begin{array}{l}\text { Mean aqueductal } \\
\text { area }\left(\mathrm{mm}^{2}\right)\end{array}$ \\
\hline Male $(n=75)$ & $5.67 \pm 2.91$ & $0.86 \pm 0.74$ & $0.017 \pm 0.014$ & $0.012 \pm 0.018$ & $0.011 \pm 0.017^{*}$ & $1.99 \pm 1.00$ \\
\hline Female $(n=62)$ & $5.23 \pm 2.76$ & $0.62 \pm 0.43$ & $0.010 \pm 0.012$ & $0.010 \pm 0.015$ & $0.005 \pm 0.006^{*}$ & $1.93 \pm 0.90$ \\
\hline Total $(n=137)$ & $5.47 \pm 2.84$ & $0.75 \pm 0.63$ & $0.015 \pm 0.013$ & $0.011 \pm 0.017$ & $0.008 \pm 0.013$ & $1.96 \pm 0.95$ \\
\hline
\end{tabular}

*Statistically significant; $p=0.002$ 
Table 2 Phase contrast MRI parameters in various age groups

\begin{tabular}{|c|c|c|c|c|c|c|}
\hline Group & $\begin{array}{l}\text { Peak velocity } \\
(\mathrm{cm} / \mathrm{sn})\end{array}$ & $\begin{array}{l}\text { Mean velocity } \\
(\mathrm{cm} / \mathrm{sn})\end{array}$ & $\begin{array}{l}\text { Forward flow } \\
\text { volume (ml) }\end{array}$ & $\begin{array}{l}\text { Reverse flow } \\
\text { volume }(\mathrm{ml})\end{array}$ & Net volume $(\mathrm{ml})$ & $\begin{array}{l}\text { Mean aqueducta } \\
\text { area }\left(\mathrm{mm}^{2}\right)\end{array}$ \\
\hline 1 (age: $1-12$ months, $n=26$ ) & $4.90 \pm 2.87$ & $0.66 \pm 0.81$ & $0.010 \pm 0.008^{\neq}$ & $0.010 \pm 0.019$ & $0.004 \pm 0.004^{\S}$ & $1.87 \pm 0.97$ \\
\hline 2 (age: $13-120$ months, $n=79$ ) & $5.99 \pm 2.97^{*}$ & $0.76 \pm 0.60$ & $0.016 \pm 0.011^{\neq}$ & $0.012 \pm 0.017$ & $0.009 \pm 0.016^{\S}$ & $1.95 \pm 0.86$ \\
\hline 3 (age: $121-202$ months, $n=32$ ) & $4.66 \pm 2.20^{*}$ & $0.80 \pm 0.54$ & $0.018 \pm 0.019^{\ddagger}$ & $0.010 \pm 0.012$ & $0.009 \pm 0.010^{\S}$ & $2.06 \pm 1.16$ \\
\hline
\end{tabular}

*Statistically significant; $p=0.027$

FStatistically significant; $p=0.039$

${ }^{\S}$ Statistically significant; $p=0.029$

Six groups were constituted according to BMI as follows: group $1(\leq 5 \%)$, group $2(6-25 \%)$, group 3 (26$50 \%)$, group $4(51-75 \%)$, group 5 (76-95\%), and group 6 (>95\%). No noteworthy differences were seen between any of these groups regarding PC-MRI parameters under investigation (Table 4).

\section{Discussion}

MRI has provided further insights and a better understanding of CSF flow dynamics. Velocity, flow, and other time-dependent variables of CSF flow may vary due to anatomy, size of vessels, systolic and diastolic blood pressure, heart rate, jugular venous blood flow, cranial tissue compliance, and respiration [13, 14]. PC-MRI is a technique that provides qualitative and quantitative evaluation of mobile fluids and has become one of the most important techniques used in the investigation of CSF flow in recent years [1]. Because contrast material and X-ray are not required, PC-MRI can easily be used in children. Elimination of the need for anesthesia in younger children is another advantage offered by PCMRI [1]. Despite the popularization of high-resolution imaging modalities, errors may still occur, especially for velocity-related parameters. These errors may insource from the nonlinear gradients, eddy flows, partial volume effects, and malpositioning of region of interest (ROI) [2, 15, 16]. PC-MRI has several limitations. Quantitative evaluation of average peak velocity, peak systolic velocity, and stroke volume is only possible in a plane perpendicular to the unidirectional flow (jets) to avoid partial volume effect. Manual segmentation methods and manual ROI placement cause intraobserver and interobserver variability in the collected data [1].
In accordance with Unal et al., we performed measurements at the ampulla, the largest portion of the cerebral aqueduct [17]. During localization of ROI, efforts were spent to keep surrounding brain tissue that has high signal pixels out of the area of measurement. As suggested by Luetmer et al., we selected velocity encoding (Venc) value as $20 \mathrm{~cm} / \mathrm{sn}$ [18]. In cases with a presumable peak velocity greater than Venc, modification may be essential. As suggested in the recent literature, we made use of prospective cardiac triggering, even if it has a longer duration of the measurement [19].

We noted that aqueductus area was significantly less in children with a smaller $\mathrm{HC}$. In children with $\mathrm{HC}<$ $5 \%$, it can be expected that cerebral aqueduct is smaller, as with the other cranial structures.

Various results have been reported in publications focusing on CSF flow dynamics [20, 21]. Unal et al. reported that, in adults and adolescents, forward flow volume, reverse flow volume, and net volume were $0.016 \pm 0.008,0.026 \pm 0.012$, and $0.010 \pm 0.007$, respectively [17]. They noted no difference regarding flow-related parameters among age groups. However, we found that forward flow volume and net volume were decreased significantly in children younger than 1 year. No difference was detected among age groups with respect to reverse flow volume. In conjunction with the publication by Unal et al., we came across no difference between boys and girls with respect to forward flow volume, reverse flow volume, and net volume [17]. In a study with PC-MRI in healthy children, the cranial, caudal, and net volume values were determined to be $0.018 \pm 0.016,0.014 \pm 0.22$, and $0.010 \pm 0.016 \mathrm{ml}$, respectively, in boys and $0.011 \pm$ $0.001, \quad 0.011 \pm 0.018$, and $0.004 \pm 0.003 \mathrm{ml}$,

Table 3 Phase contrast MRI parameters in children with head circumference $(\mathrm{HC})<3 \%$ and $\mathrm{HC}$ between 3-95\%

\begin{tabular}{|c|c|c|c|c|c|c|}
\hline Group & $\begin{array}{l}\text { Peak velocity } \\
(\mathrm{cm} / \mathrm{sn})\end{array}$ & $\begin{array}{l}\text { Mean velocity } \\
(\mathrm{cm} / \mathrm{sn})\end{array}$ & $\begin{array}{l}\text { Forward flow } \\
\text { volume (ml) }\end{array}$ & $\begin{array}{l}\text { Reverse flow } \\
\text { volume (ml) }\end{array}$ & Net volume (ml) & $\begin{array}{l}\text { Mean aqueducta } \\
\text { area }\left(\mathrm{mm}^{2}\right)\end{array}$ \\
\hline $1(\mathrm{HC}<3 \%, n=25)$ & $4.75 \pm 3.47$ & $0.74 \pm 0.72$ & $0.011 \pm 0.012^{*}$ & $0.011 \pm 0.027^{\ddagger}$ & $0.005 \pm 0.008^{\S}$ & $1.62 \pm 0.70^{\mu}$ \\
\hline 2 ( $\mathrm{HC}$ between $3-95 \%, n=112$ ) & $5.63 \pm 2.67$ & $0.75 \pm 0.61$ & $0.016 \pm 0.013^{*}$ & $0.011 \pm 0.013^{\ddagger}$ & $0.009 \pm 0.014^{\S}$ & $2.04 \pm 0.99^{\mu}$ \\
\hline
\end{tabular}

\section{$H C$ head circumference}

*Statistically significant; $p=0.008$

FStatistically significant; $p=0.026$

${ }^{\S}$ Statistically significant; $p=0.032,0.038$

${ }^{\mu}$ statistically significant; $p=0.003$ 
Table 4 An overview of phase contrast MRI parameters in various body mass index (BMI) groups

\begin{tabular}{|c|c|c|c|c|c|c|}
\hline Group & $\begin{array}{l}\text { Peak velocity } \\
(\mathrm{cm} / \mathrm{sn})\end{array}$ & $\begin{array}{l}\text { Mean velocity } \\
(\mathrm{cm} / \mathrm{sn})\end{array}$ & $\begin{array}{l}\text { Forward flow } \\
\text { volume (ml) }\end{array}$ & $\begin{array}{l}\text { Reverse flow } \\
\text { volume (ml) }\end{array}$ & Net volume (ml) & $\begin{array}{l}\text { Mean aqueductal } \\
\text { area }\left(\mathrm{mm}^{2}\right)\end{array}$ \\
\hline $1(\mathrm{BMI} \leq 5 \%, n=20)$ & $5.11 \pm 2.20$ & $0.79 \pm 0.50$ & $0.013 \pm 0.009$ & $0.008 \pm 0.005$ & $0.007 \pm 0.006$ & $0.018 \pm 0.007$ \\
\hline 2 (BMI between $6-25 \%, n=33$ ) & $5.46 \pm 3.16$ & $0.76 \pm 0.66$ & $0.015 \pm 0.013$ & $0.013 \pm 0.024$ & $0.007 \pm 0.008$ & $0.018 \pm 0.008$ \\
\hline 3 (BMI between 26-50\%, $n=36$ ) & $5.19 \pm 2.87$ & $0.77 \pm 0.83$ & $0.014 \pm 0.010$ & $0.010 \pm 0.011$ & $0.006 \pm 0.005$ & $0.020 \pm 0.009$ \\
\hline 4 (BMI between $51-75 \%, n=26$ ) & $5.88 \pm 3.08$ & $0.69 \pm 0.51$ & $0.018 \pm 0.019$ & $0.011 \pm 0.012$ & $0.011 \pm 0.021$ & $0.022 \pm 0.013$ \\
\hline 5 (BMI between 76-95\%, $n=79$ ) & $5.71 \pm 2.98$ & $0.83 \pm 0.47$ & $0.018 \pm 0.017$ & $0.012 \pm 0.013$ & $0.015 \pm 0.024$ & $0.019 \pm 0.007$ \\
\hline $6(\mathrm{BMI}>95 \%, n=32)$ & $5.92 \pm 1.96$ & $0.55 \pm 0.45$ & $0.010 \pm 0.003$ & $0.021 \pm 0.034$ & $0.003 \pm 0.002$ & $0.011 \pm 0.006$ \\
\hline
\end{tabular}

respectively, in girls [16]. The cranial and net volume values were found to be higher in boys. However, in this study, the relationship of CSF flow parameters with BMI and head circumference was not evaluated. We detected that mean net volume was decreased in girls.

In adults, peak velocity is reported to range between 1.5 and $12.7 \mathrm{~cm} / \mathrm{sn}[15,17]$. Iskandar et al. analyzed peak velocities of 10 children (age range: 3-16 months) at the level of the foramen magnum and found a mean velocity of $6.9 \mathrm{~cm} / \mathrm{sn}$ [22]. Furthermore, they detected a decrease in peak velocity with advancement of age. Our results indicated that there was no difference between group 1 (age: 1-12 months) and group 2 (age: 13-120 months). However, the decrease in peak velocity with the advancement of age was obvious when group 2 and group 3 (age: 121-202 months) were compared.

There were no differences in CSF flow parameters in various age and gender groups. In the present study, peak velocities were found to be faster in obese cases. However, the number of obese children in the study was small $(n=7)$, so further trials on obese children are warranted to achieve clues on the link between BMI and CSF flow.

No difference was observed in terms of mean and peak velocities between children with $\mathrm{HC}<3 \%$ and children with $\mathrm{HC}$ between $3 \%$ and $95 \%$. Owing to the fact that there were no children with $\mathrm{HC}>95 \%$, no conclusions can be drawn for children with macrocephaly.

Limitations of the present study include small sample size, the variability of CSF flow dynamics, and data limited to the experience of a single institution. Moreover, it was proposed that an accurate assessment necessitates an aqueductal diameter of $1.5 \mathrm{~mm}^{2}$ [23]. Even though the mean diameter was $1.96 \mathrm{~mm}^{2}$, some of our cases had aqueductal area smaller than $1.5 \mathrm{~mm}^{2}$. Finally, the probable influence of anesthesia on the measuring method in children necessitating anesthesia is neglected in our study.

\section{Conclusion}

To conclude, BMI and HC may be associated with CSF flow dynamics in children. A smaller $\mathrm{HC}$ is accompanied with a lower forward flow volume, reverse flow volume, net volume, and aqueductal diameter. These points should be remembered during the design of further trials on determinants of CSF flow in children.

\section{Abbreviations}

BMI: Body mass index; HC: Head circumference; CSF: Cerebral spinal fluid; PCMRI: Phase contrast magnetic resonance imaging; SPSS: Statistical Package for the Social Science

\section{Acknowledgements}

The authors would like to thank all the personnel who contributed in this study.

\section{Authors' contributions}

GD, SBG shared in the study conception and design, collecting patients' data, processing MRI findings at the MRI work station, and shared in writing and correcting the manuscript and revision. MÖ, BK shared in the study conception and design, acquisition of data, analysis and interpretation of data, and drafting of manuscript. AS, SG shared in the study conception and design, clinical examination, acquisition of data, analysis and interpretation of data, and drafting of the manuscript. All authors read and approved the final manuscript.

Funding

This study had no funding from any resource.

\section{Availability of data and materials}

The datasets used and/or analyzed during the study are available upon reasonable request.

\section{Ethics approval and consent to participate}

No individual data was included in the study.

The approval of the local Institutional Review Board (2014/208) has been obtained prior to the study.

All patients included in this study gave verbal informed consent to participate in this research.

If the patient was unconscious at the time of the study, written informed consent for their participation was given by their legal guardian.

\section{Consent for publication}

All patients included in this study gave written informed consent to publish the data contained within this study.

If the patient was unconscious when consent for publication was requested, written informed consent for the publication was given by their legal guardian.

\section{Competing interests}

The authors declare that they have no competing interests.

\section{Author details}

${ }^{1}$ Department of Radiology, Faculty of Medicine, Inonu University, Elazig Road, 15 km, 44100 Malatya, Turkey. ${ }^{2}$ Department of Radiology, Division of Pediatric Radiology, Faculty of Medicine, Selcuk University, Alaeddin Keykubat Yerleşkesi, Akademi Mah, Yeni Istanbul Street No: 369, Konya, Turkey. ${ }^{3}$ Department of Radiology, Erciyes University School of Medicine, Kayseri, 
Turkey. ${ }^{4}$ Department of Pediatric Neurology, Faculty of Medicine, Inonu University, Elazig Road, 15 km 44100, Malatya, Turkey.

Received: 3 April 2020 Accepted: 9 June 2020

Published online: 19 June 2020

\section{References}

1. Korbecki A, Zimny A, Podgórski P, Sąsiadek M, Bladowska J (2019) Imaging of cerebrospinal fluid flow: fundamentals, techniques, and clinical applications of phase-contrast magnetic resonance imaging. Pol J Radiol 13: e240-e250

2. Atasoy B, Aralasmak A, Cetinkaya E, Toprak H, Toprak A, Tokdemir S, Babacan G, Alkan A (2020) Normal pressure hydrocephalus: clinical symptoms, cerebrospinal fluid flow metrics and white matter changes. J Comput Assist Tomogr 44(1):59-64

3. Bapuraj JR, Londy FJ, Delavari N, Maher CO, Garton HJ, Martin BA, Muraszko KM, el-SH I, Quint DJ (2016) Cerebrospinal fluid velocity amplitudes within the cerebral aqueduct in healthy children and patients with Chiari I malformation. J Magn Reson Imaging 44:463-470

4. Chen G, Zheng J, Xiao Q, Liu Y (2013) Application of phase-contrast cine magnetic resonance imaging in endoscopic aqueductoplasty. Exp Ther Med 5:1643-1648

5. Mohammad SA, Osman NM, Ahmed KA (2019) The value of CSF flow studies in the management of CSF disorders in children: a pictorial review. Insights Imaging 10(1):3

6. Akay R, Kamisli O, Kahraman A, Oner S, Tecellioglu M (2015) Evaluation of aqueductal CSF flow dynamics with phase contrast cine MR imaging in idiopathic intracranial hypertension patients: preliminary results. Eur Rev Med Pharmacol Sci 19(18):3475-3479

7. Ünlü S, Doğan M, Kapicioğlu Y, Kamişli S, Öner S, Yildirim IO, Öztürk M (2017) CSF flow patterns in the brain in patients with neuro-Behçet disease and Behçet disease. Eur Rev Med Pharmacol Sci 21(17):3906-3910

8. Sass LR, Khani M, Romm J, Schmid Daners M, McCain K, Freeman T, Carter GT, Weeks DL, Petersen B, Aldred J, Wingett D, Martin BA (2020) Noninvasive MRI quantification of cerebrospinal fluid dynamics in amyotrophic lateral sclerosis patients. Fluids Barriers CNS 17(1):4

9. Corte AD, de Souza CFM, Anés M, Maeda FK, Lokossou A, Vedolin LM, Longo MG, Ferreira MM, Perrone SGP, Balédent O, Giugliani R (2017) Correlation of CSF flow using phase-contrast MRI with ventriculomegaly and CSF opening pressure in mucopolysaccharidoses. Fluids Barriers CNS 14(1):23

10. Berdahl JP, Fleischman D, Zaydlarova J, Stinnett S, Allingham RR, Fautsch MP (2012) Body mass index has a linear relationship with cerebrospinal fluid pressure. Invest Ophthalmol Vis Sci 53:1422-1427

11. Prince $M$, Acosta $D$, Dangour AD, Uauy R, Guerra M, Huang $Y$, Jacob KS, Rodriguez JJ, Salas A, Sosa AL, Williams JD, Acosta I, Albanese E, Dewey ME, Ferri CP, Stewart R, Gaona C, Jotheeswaran AT, Kumar PS, Li S, Guerra JC, Rodriguez D, Rodriguez G (2011) Leg length, skull circumference, and the prevalence of dementia in low and middle income countries: a 10/66 population-based cross sectional survey. Int Psychogeriatr 23(2):202-213

12. Hoffmann E, Warmuth-Metz M (2000) Phase-contrast MR imaging of the cervical CSF and spinal cord: volumetric motion analysis in patients with Chiari 1 malformation. AJNR 21:151-158

13. Wagshul ME, Eide PK, Madsen JR (2011) The pulsating brain: a review of experimental and clinical studies of intracranial pulsatility. Fluids Barriers CNS 8:5

14. Ichikawa S, Motosugi U, Okumura A, Shimizu T, Onishi H (2018) Measurement of cerebrospinal fluid flow dynamics using phase contrast MR imaging with bilateral jugular vein compression: a feasibility study in healthy volunteers. Magn Reson Med Sci 17(3):265-268

15. Lee JH, Lee HK, Kim JK, Kim HJ, Park JK, Choi CG (2004) CSF flow quantification of the cerebral aqueduct in normal volunteers using phase contrast cine MR imaging. Korean J Radiol 5:81-86

16. Öztürk M, Sığırcı A, Ünlü S (2016) Evaluation of aqueductal cerebrospinal fluid flow dynamics with phase-contrast cine magnetic resonance imaging in normal pediatric cases. Clin Imaging 40(6):1286-1290

17. Unal O, Kartum A, Avcu S, Etlik O, Arslan H, Bora A (2009) Cine phasecontrast MRI evaluation of normal aqueductal cerebrospinal fluid flow according to sex and age. Diagn Interv Radiol 15:227-231

18. Luetmer PH, Huston J, Friedman JA, Dixon GR, Petersen RC, Jack CR, McClelland RL, Ebersold MJ (2002) Measurement of cerebrospinal fluid flow at the cerebral aqueduct by use of phase-contrast magnetic resonance imaging: technique validation and utility in diagnosing idiopathic normal pressure hydrocephalus. Neurosurgery 50:534-542

19. Enzmann DR, Pelc NJ (1993) Cerebrospinal fluid flow measured by phasecontrast cine MR. AJNR Am J Neuroradiol 14:1301-1307

20. Capel C, Makki M, Gondry-Jouet C, Bouzerar R, Courtois V, Krejpowicz B, Balédent O (2014) Insights into cerebrospinal fluid and cerebral blood flows in infants and young children. J Child Neurol 29(12):1608-1615

21. Barkhof F, Kouwenhoven M, Scheltens P (1994) Phase-contrast cine MR imaging of normal aqueductal CSF flow. Effect of aging and relation to CSF void on modulus MR. Acta Radiol 35:123-130

22. Iskandar BJ, Haughton V (2005) Age-related variations in peak cerebrospinal fluid velocities in the foramen magnum. J Neurosurg 103:508-511

23. Brinkmann G, Harlandt O, Muhle C, Brossmann J, Heller M (2000) Quantification of fluid flow in magnetic resonance tomography: an experimental study of a flow model and liquid flow measurements in the cerebral aqueduct in volunteers. Rofo 172:1043-1051

\section{Publisher's Note}

Springer Nature remains neutral with regard to jurisdictional claims in published maps and institutional affiliations.

\section{Submit your manuscript to a SpringerOpen ${ }^{\odot}$ journal and benefit from:}

- Convenient online submission

- Rigorous peer review

- Open access: articles freely available online

High visibility within the field

- Retaining the copyright to your article

Submit your next manuscript at $>$ springeropen.com 